\title{
Analisis Efisiensi Teknis Sapi Potong di Kabupaten Kupang Provinsi Nusa Tenggara Timur
}

\author{
Mardit Nikodemus Nalle \\ ${ }^{a}$ Fakultas Pertanian, Universitas Timor, Kefamenanu, TTU - NTT, Indonesia.
}

\section{Article Info}

\section{Article history:}

Received 12 April 2016

Received in revised form 27 Juni 2016

Accepted 3 Juli 2016

\section{Keywords:}

Efisiensi Teknis

Sapi Potong

Kupang

\section{Abstrak}

Tujuan dari penelitian ini untuk menganalisis efisiensi teknis sapi potong di Kabupaten Kupang-Nusa Tenggara Timur. Metode penelitian dan metode pengambilan sampel dilakukan secara purposive dengan mengambil 76 respoden. Lokasi penelitian dilakukan di Keca matan Amarasi (Kelurahan Nonbes, Desa Ponain, Desa Kotabes, dan Desa Tesbatan). Faktor-faktor yang berpengaruh pada penggemukan sapi di Kabupaten Kupang yaitu bobot awal, pakan, vitamin dan aquades sedangkan tenaga kerja dan obat-obatan tidak berpengaruh. Usaha penggemukan sapi di Kabupaten Kupang secara teknis menunjukkan efisien dengan nilai rata-rata efisiensi teknis sebesar 0,982 dan skala usaha menunjukkan skala Decreasing return to scale. Nilai gamma $(\gamma)$ menunjukkan bahwa 44,80 persen error term dari fungsi produks frontier disebabkan oleh faktor internal seperti umur peternak, pengalaman, tingkat pendidikan dan modal sedangkan 55,20 persen disebabkan oleh noise terhadap cuaca dan penyakit. Faktor-faktor yang dapat menangkap efek inefisensi teknis adalah umur peternak, tingkat pendidikan dan modal sedangkan pengalaman beternak tidak menangkap efek inefisiensi teknis. (02016 dipublikasikan oleh Agrimor.

\section{Pendahuluan}

Sapi potong merupakan salah satu komoditi unggulan di Kabupaten Kupang Provinsi Nusa Tenggara Timur (NTT) setelah tanaman bahan pangan. Kupang juga merupakan salah satu sentra produksi sapi potong hingga 2012 populasi sapi potong di Kabupaten Kupang mengalami peningkatan dengan populasi sap mencapai 158203 ekor (BPS, 2013). Peningkatan populasi sapi dapa meningkatkan peningkatan PDRB bagi Kabupaten Kupang sebesar 3,01 \% dan tambahan lapangan kerja sebesar 44,04\%.

Peningkatan populasi sapi potong belum menunjukkan produktivitas sapi di Kabupaten Kupang. Hal ini disebabkan penggunaan input pakan yang berasa dari alam, manajemen peternakan yang masih sederhana dan pengaruh eksterna seperti kemarau panjang dan penyakit. Manajemen peternakan yang sederhana menyebabkan penggemukan sapi di Kabupaten Kupang lama dengan rata-rata penggemukan hingga 18 bulan sedangkan penggemukan sapi yang singkat dengan manajemen peternakan yang baik hanya berlangsung 3-4 bulan (Sarwono \& Arianto, 2011). Hal ini menyebabkan pertambahan bobot sapi potong d Kabupaten Kupang mencapai 0,2-0,4 kg/ekor sedangkan pertambahan bobot sap yang optimal untuk sapi bali dapat mencapai 0,3-0,6 kg/ekor. Tujuan dar penelitian ini adalah untuk melihat efisiensi teknis dari penggemukan sapi $\mathrm{d}$ Kabupaten Kupang-Nusa Tenggara Timur. Menurut Nulik et al., (2004) musim kemarau yang panjang sekitar 8-9 bulan menyebabkan produksi pakan di lahan penggembalaan dan lahan hutan mengering sehingga berpengaruh terhadap pertumbuhan sapi potong di Kabupaten Kupang, Provinsi NTT.

Penelitian ini bertujuan untuk menganalisis efisiensi teknis sapi potong di Kabupaten Kupang, Provinsi NTT.

\section{Metode}

Penelitian ini dilaksanakan bulan Februari-Mei 2013 di Kecamatan Amaras Kabupaten Kupang-Nusa Tenggara Timur. Metode penelitian dilakukan secara purposive dengan mengambil garis batas terhadap wilayah penggemukan sap potong (Saunders, 2009). Data yang digunakan data primer dan data sekunder. Pengambilan sampel peternak sapi potong di tingkat penggemukan di Kabupaten Kupang dilakukan secara purposive terhadap 76 peternak yang terdiri atas 32 peternak di Kelurahan Nonbes, 29 peternak di Desa Ponain, 8 peternak di Desa Kotabes, dan 9 peternak di Desa Tesbatan. Data yang diperoleh diolah dengan menggunakan metode kuantitatif. Proses analisis data primer diolah dengan menggunakan program Microsoft Excel, SAS 9.1 dan Frontier 4.1.

\section{Hasil dan Pembahasan}

\subsection{Keragaan Peternak Sapi Potong di Kecamatan Amarasi}

Dari 76 peternak di Kecamatan Amarasi (Kelurahan Nonbes, Desa Ponain, Desa Kotabes dan Desa Tesbatan) Kabupaten Kupang-Nusa Tenggara Timur Berdasarkan data primer terdapat 38 peternak yang berusia $\leq 50$ tahun $(50 \%)$ dan 38 peternak yang berusia $>50$ tahun $(50 \%)$. Tingkat pendidikan bahwa peternak yang pendidikan sampai dengan tamat Sekolah Dasar berjumlah 46 orang $(60,52 \%)$, peternak yang pendidikan dari Tingkat Sekolah Lanjutan Tingkat Pertama sampai dengan tamat Sekolah Menengah Umum berjumlah 27 orang $(35,52 \%)$, peternak yang pendidikan hingga tamat perguruan tingg (Jenjang Diploma hingga doktor) berjumlah 3 orang $(3,96 \%)$. Berdasarkan jenis kelamin bahwa peternak yang bekerja di sektor on farm untuk jenis kelamin lakilaki berjumlah 69 orang $(90,79 \%)$ dan peternak yang berjenis kelamin perempuan berjumlah 7 orang $(9,21 \%)$. Berdasarkan pengalaman beternak maka peternak yang memiliki pengalaman beternak sapi selama $\leq 15$ tahun berjumlah 45 orang $(59,21 \%)$ dan peternak yang memiliki pengalaman beternak sapi selama $>15$ tahun sebesar 31 orang $(40,79 \%)$. Jika dilihat berdasarkan kepemilikan ternak sapi maka peternak sapi yang hanya memiliki sapi 1-4 ekor berjumlah 31 orang $(40,79 \%)$, peternak yang memiliki ternak sapi antara 5-10 ekor berjumlah 37 orang $(48,69 \%)$, peternak yang memiliki ternak sapi lebih dari 10 ekor berjumlah 8 orang $(10,52 \%)$, dan jika dilihat dari luas lahan yang digunakan untuk pakan ternak maka jumlah luas lahan yang diperoleh oleh peternak dari 76 responden di Kecamatan Amarasi (Kelurahan Nonbes, Desa Ponain, Desa Kotabes dan Desa Tesbatan) sebesar 11,66 hektar.

\subsection{Faktor-Faktor Produksi Fisik Sapi Potong}

Data deskriptif penggunaan input produksi sapi potong yang dikembangbiakan di Kecamatan Amarasi (Kelurahan Nonbes, Desa Ponain, Desa Kotabes, Desa Tesbatan) yaitu bobot awal, pakan, tenaga kerja, vitamin (Bkompleks), obat-obatan (theramycin dan tetramisol) dan aquades. Hasil dari penelitian menunjukan bahwa rata-rata bobot awal sapi potong di wilayah penelitian sebesar $149 \mathrm{~kg}$ dan rata-rata bobot akhir berjumlah 298 sehingga pertambahan bobot badan di wilayah penelitian (Kelurahan Nonbes, Desa Ponain, Desa Kotabes dan Desa Tesbatan) sebesar 149 kg. Rata-rata pakan yang dikonsumsi oleh sapi di wilayah penelitian adalah $28,65 \mathrm{~kg}$ dengan rata-rata lama penggemukan selama 259 hari. Jenis pakan yang dikonsumsi peternak di lokas penelitian adalah lamtoro, rumput-rumputan seperti rumput gajah dan rumput raja, batang pisang dan daun pisang, daun singkong, dan ubi. Penggunaan konsentrat tidak dikonsumsi oleh sapi potong yang dikembangbiakan di wilayah penelitian. Tenaga kerja yang dikerjakan oleh peternak di kecamatan Amarasi adalah Tenaga Kerja Dalam Keluarga. Rata-rata jam kerja sehari yang yang dikerjakan oleh satu orang dalam mengembangbiakan ternak sapi dari proses perkandangan dan penggembalaan selama 5 jam untuk satu tenaga kerja atau $0,63 \mathrm{HOK}$ atau rata-rata 1266 jam selama 259 hari. Sapi yang degemukan dikandangkan yang terbuat dari kayu dan daun gewang dengan ukuran $2 \times 1,5 \mathrm{~m}$

Obat-obatan yang diberikan oleh peternak sapi di Kecamatan Amarasi adalah tetramisol atau theramycin dengan perbandingan penyemprotan dengan aquades sebesar 1 : 5. Rata-rata pemberikan tetramisol adalah $128 \mathrm{mg}$ dengan rata-rata penyuntikan selama $17 \mathrm{kali}$ atau dalam seminggu dua kali dengan ratarata penyuntikan sebanyak $7,73 \mathrm{mg}$. Vitamin yang diberikan adalah vintamin $\mathrm{b}$ kompleks dengan pemberian sebanyak 17 kali penyuntikan sebesar $126 \mathrm{mg}$ atau dalam satu kali penyuntikan dapat diberikan sebanyak 7,76 mg. Dan aquades yang diberikan pada ternak sapi sebanyak 1 gram per ekor sapi jika dibutuhkan untuk ditambahkan pada vitamin atau obat-obatan dengan perbandingan 0,02 gram untuk bobot badan sapi dengan kenaikan $10 \mathrm{~kg}$ bobot badan sapi.

\subsection{Faktor-Faktor Produksi Sapi Potong}

Berdasarkan hasil analisis faktor-faktor produksi yang berpengaruh terhadap penggemukan sapi potong di Kecamatan Amarasi (Kelurahan Nonbes, Desa Ponain, Desa Kotabes, Desa Tesbatan).

Tabel 1. Pendugaan OLS Fungsi Produksi Cobb Douglas Frontier di Kecamatan Amarasi Kabupaten Kupang

\begin{tabular}{|c|c|c|c|c|c|}
\hline Variabel & Cooficient & t-vlaue OLS & $\begin{array}{l}\text { t-value } \\
\text { MLE }\end{array}$ & Prob & VIF \\
\hline Konstanta & 10,0773 & 2,59 & 12,90496 & 0,0117 & 0 \\
\hline Bobot awal $\left(\mathrm{X}_{1}\right)$ & 0,23773 & $3,18^{\mathrm{b}}$ & 0,206796 & 0,0022 & 5,30306 \\
\hline Pakan $\left(\mathrm{X}_{2}\right)$ & 0,12125 & $2,29^{\mathrm{b}}$ & 0,094085 & 0,0253 & 4,11565 \\
\hline Tenaga Kerja $\left(\mathrm{X}_{3}\right)$ & 0,11962 & 1,57 & 0,117775 & 0,1208 & 2,71735 \\
\hline $\operatorname{Vitamin}\left(\mathrm{X}_{4}\right)$ & 0,15194 & $2,58^{\mathrm{b}}$ & 0,154671 & 0,0121 & 2,99457 \\
\hline Obat-obatan $\left(\mathrm{X}_{5}\right)$ & 0,00082649 & 0,02 & 0,023888 & 0,9842 & 1,40440 \\
\hline Aquades $\left(\mathrm{X}_{6}\right)$ & 0,34646 & $4,78^{\mathrm{a}}$ & 0,392146 & $<, 0001$ & 2,76003 \\
\hline F-hitung & $95,32^{\mathrm{a}}$ & & & $<0,0001$ & \\
\hline R-square & 0,8923 & \multicolumn{3}{|c|}{ sigma-square } & 0,00407 \\
\hline Durbin Watson & 1,961 & \multicolumn{3}{|c|}{ gamma MLE } & 0,448 \\
\hline \multirow[t]{3}{*}{$\Sigma$ bi } & 0,978 & \multicolumn{3}{|c|}{ log-likelihood OLS } & 113,93 \\
\hline & & \multicolumn{3}{|c|}{ log-likelihood MLE } & 120,77 \\
\hline & & \multicolumn{3}{|c|}{ LR-test of the one side error } & 13,66 \\
\hline
\end{tabular}

Keterangan: a kriteria selang kepercayaan 99\% dan b kriteria selang kepercayaan $95 \%$

Sumber: Data Primer 2013

Hasil penelitian menunjukkan pertambahan bobot badan sapi potong di Kecamatan Amarasi (Kabupaten Kupang NTT dapat dilihat dengan menggunakan fungsi produksi cobb douglas frontier dapat diambil keputusan sebagai berikut : 1) nilai $R$-square dari penelitian tersebut sebesar 89,23 persen yang berarti pertambahan bobot sapi potong di Kabupaten Kupang-NTT dapat dijelaskan oleh bobot awal sapi potong, pakan, tenaga kerja, vitamin, obat-obatan 
dan aquades sedangkan sebesar 10,77 persen keragaman pertambahan sapi potong hanya dapat dijelaskan di luar model; 2) Nilai ragam (uji f-hitung) dimana pertambahan bobot sapi potong di Kabupaten Kupang dipengaruhi oleh bobot awal sapi potong, pakan, tenaga kerja, vitamin, obat-obatan dan aquades. Nilai F-hitung pada penelitian ini sebesar 95,32 dengan nilai f-tabel pada tingkat kepercayaan 99 persen $(\alpha$ 1\%) sebesar 3,08 atau nilai p-value $<0,001$ yang berarti pertambahan bobot badan sapi potong dipengaruhi oleh, bobot awal sapi, pakan, tenaga kerja, vitamin, obat-obatan dan aquades.

Uji hipotesis ketiga dengan melakukan uji parsial faktor produksi yang berpengaruh terhadap pertambahan bobot sapi. Kriteria Uji t digunakan untuk menentukan tiap-tiap faktor produksi dari bobot awal, pakan, tenaga kerja, vitamin, obat-obatan dan aquades yang berpengaruh terhadap pertambahan bobot sapi yaitu dengan tingkat kepercayaan 95 persen ( $\alpha$ 5\%). Hasil ini menunjukkan faktor produksi yang berpengaruh terhadap pertambahan bobot badan sapi di Kecamatan Amarasi (Kelurahan Nonbes, Desa Ponain, Desa Kotabes, dan Desa Tesbatan) adalah bobot awal sapi, pakan, vitamin dan aquades sedangkan tenaga kerja dan obat-obatan tidak berpengaruh terhadap pertambahan bobot badan sapi potong. Pertama, faktor produksi bobot badan sapi dilihat dari $\mathrm{p}$-value sebesar 0,0022 maka bobot awal sapi dapat memberikan pengaruh terhadap pertambahan bobot badan sapi dimana setiap bertambahnya bobot awal sapi dengan umur tertentu dapat memberikan kenaikan bobot badan sebesar $0,23773 \mathrm{~kg}$ dimana semakin besar bobot awal sapi bali yang digemukkan dengan kondisi sapi yang sehat akan memberikan pengaruh terhadap pertambahan bobot badan sapi; Kedua, pakan dimana nilai p-value sebesar 0,0253 jika dibandingkan dengan nilai $\alpha$ 5\% maka pakan berpengaruh terhadap pertambahan bobot badan sapi setiap pertambahan $1 \mathrm{~kg}$ pakan akan memberikan pertambahan bobot badan sapi sebesar $0,12125 \mathrm{~kg}$; ketiga, TK kerja dimana nilai p-value TK sebesar 0,1208 jika dibandingkan dengan nilai $\alpha 5 \%$ maka TK tidak berpengaruh terhadap pertambahan bobot badan sapi. Kondisi ini karena penggemukan sapi dengan rata-rata waktu kerja 5 jam sehari tidak memberikan pengaruh terhadap kenaikan bobot badan sapi potong; keempat, vitamin dimana nilai p-value sebesar 0,0127 jika dibandingkan dengan nilai $\alpha 5 \%$ maka vitamin berpengaruh terhadap pertambahan bobot badan sapi. Hal ini dapat disimpulkan bahwa setiap pemberian $1 \mathrm{mg}$ vitamin akan memberikan kenaikan bobot badan sapi sebesar $0,15194 \mathrm{~kg}$. pemberian vitamin 7,73 mg setiap kali penyuntikan memberikan hasil positif terhadap pertambahan bobot sapi hingga periode penggemukan; kelima, obat-obatan dimana nilai p-value sebesar 0,9842 jika dibandingkan dengan $\alpha 5 \%$ maka obat-obatan tidak berpengaruh terhadap pertambahan bobot sapi. Hal ini dikarenakan pemberian obat-obatan yang disuntik sebanyak 7,76 kali untuk satu ekor tidak memberikan efek terhadap penggemukan sapi potong; aquades, dimana nilai p-value terhadap penggemukan sapi sebesar $<0,0001$ jika dibandingkan dengan $\alpha 1 \%$ maka aquades dapat berpengaruh terhadap pertambahan bobot badan sapi. Hal ini dikarenakan setiap pertambahan $1 \mathrm{~g}$ vitamin akan meningkatkan pertambahan bobot badan sapi sebesar $0,34646 \mathrm{~kg}$. Pemberian aquades dapat memberikan pertambahan bobot badan yang positif jika disuntik bersama vitamin b-Kompleks karena cairan yang dimaksud dapat memberikan pengaruh terhadap peningkatan bobot badan yang relatif cepat.

Tahap pengujian selanjutnya adalah dengan melihat uji OLS berdasarkan aturan goodness of fit yang disebut BLUE (Best Linier Unbiased Estimator). Asumsi penelitian ini sudah memenuhi syarat Cobb-Douglas dimana tidak terdapat multikolinearitas dari variabel eksogen dengan nilai VIF di bawah nilai 10 dan nilai durbin Watson tidak terjadi autokorelasi dimana DU $=1,8011$ dan nilai $\mathrm{Dw}=1,960$ dimana kriteria uji adalah 1,8011 $<1,960<2,040$. Dalam pemodelan ini sudah memenuhi syarat Cobb-Douglas dengan nilai $\Sigma \beta \mathrm{i}=0,978$ yang berarti kondisi ini memenuhi syarat Decreasing Return to Scale. Kondisi ini masih memberikan syarat constant return to scale dengan memperkirakan tambahan input untuk menghasilkan output yang konstan sehingga dapat berlaku syarat constant return to scale atau Cobb Douglas. Kondisi constant return to scale menunjukkan bahwa setiap tambahan input produksi yang diberikan akan menghasilkan tambahan output yang tetap (MPP/APP =1) (Debertin, 1986).

Berdasarkan hasil analisis fungsi produksi stochastic frontier menunjukkan efek inefisensi terhadap pertambahan bobot sapi potong di Kecamatan Amarasi (Kelurahan Nonbes, Desa Ponain, Desa Kotabes dan Desa Tesbatan menunjukkan nilai sigma square $\left(\Sigma^{2}\right)$ dari penelitian ini adalah 0,00407 yang berarti bahwa nilai error term dari penggemukan sapi potong semakin menunjukkan bahwa hal ini sudah sesuai dengan kondisi yang ada di lapangan sehingga nilai (ui) yang mendekati nol berarti sudah terdistribusi normal. Nilai gamma $(\gamma)$ dalam penelitian ini 0,448 yang berarti sebesar 44,80 persen error term di dalam fungsi produksi disebabkan karena faktor internal (ui) seperti umur peternak, pengalaman beternak, pendidikan sedangkan 55,20 persen disebabkan oleh faktor noise (vi) seperti iklim, cuaca, penyakit ternak. Nilai generalized rasio dalam penelitian ini adalah 13,66 sedangkan nilai tabel codde and palm dalam penelitian tersebut dengan selang kepercayaan 95 persen sebesar 12,59 hal ini menggambarkan fungsi produksi sapi potong di tingkat penggemukan sudah terdistribusi normal. Hal ini dapat dilihat juga dari nilai Likelihood ratio dari MLE sebesar 120,77 dan nilai likelihood ratio dari OLS sebesar 113,93 menunjukkan bahwa analisis pertambahan bobot badan sapi sudah terdistribusi normal.

\subsection{Efisiensi Teknis Penggemukan Sapi Potong}

Nilai efisiensi teknis pada penelitian sapi potong di Kecamatan Amaras Kabupaten Kupang Nusa Tenggara Timur tertinggi sebesar 0,995 sedangkan nilai terendah adalah 0,865 dengan rata-rata efisiensi teknis sebesar 0,971 . Hal ini berarti rata-rata penggemukan sapi potong di Kecamatan Amarasi Kabupaten Kupang Nusa Tenggara Timur secara teknis sudah efisien. Hasil analisis menunjukkan bahwa skala efisiensi teknis peternak dari 0.80-0,919 berjumlah 2 peternak $(2,84$ persen), skala efisiensi teknis penggemukan sapi potong dari $0,920-0,980$ berjumlah 13 orang (17,10 persen) dan skala efisiensi penggemukan sapi potong dari 0,981-1 adalah 61 orang ( 80,26 persen). Hal ini menunjukkan bahwa penggunaan input produksi sapi potong yang dilakukan oleh peternak sapi di Kecamatan Amarasi sudah efisien dimana nilai efisiensi teknis yang diharapkan terhadap penggunaan input lebih besar dari 0,8 (Coelli et al., 2005).

Sumber-sumber inefisiensi dalam penelitian ini adalah ini adalah status peternakan sapi di Nusa Tenggara Timur adalah umur peternak $\left(z_{1}\right)$, pengalaman beternak $\left(\mathrm{z}_{2}\right)$, tingkat pendidikan $\left(\mathrm{z}_{3}\right)$ dan modal $\left(\mathrm{z}_{4}\right)$. Nilai parameter inefisiensi teknis penggemukan sapi potong dapat disajikan pada Tabel 2.

Tabel 2. Nilai Parameter dari Inefisiensi Teknis Penggemukan Sapi di Kecamatan Amarasi

\begin{tabular}{lll}
\hline Variabel & Coeficient & t-ratio \\
\hline Intercept & $-0,0397$ & $-0,1236$ \\
Umur peternak $\left(\mathrm{z}_{1}\right)$ & $-0,1856$ & $-1,885^{\mathrm{b}}$ \\
Pengalaman $\left(\mathrm{z}_{2}\right)$ & $-0,022$ & $-0,889$ \\
Pendidikan $\left(\mathrm{z}_{3}\right)$ & 0,311 & $1,87^{\mathrm{b}}$ \\
Modal $\left(\mathrm{z}_{4}\right)$ & 0,09084 & $2,03^{\mathrm{b}}$ \\
\hline
\end{tabular}

Tabel 2. menunjukkan nilai bahwa nilai efek inefisiensi dari penggemukan sapi di Kecamatan Amarasi (Kelurahan Nonbes, Desa Ponain, Desa Kotabes dan Desa Tesbatan) terdiri atas umur, Pengalaman, pendidikan dan modal. Nilai t ratio menunjukkan bahwa faktor-faktor yang dapat menangkap nilai inefisiensi teknis adalah umur peternak, pendidikan dan modal sedangkan pengalaman tidak dapat menangkap inefisiensi teknis tersebut. Tanda positif vektor error term menunjukkan bahwa semakin tinggi faktor produksi maka meningkatkan inefisiensi teknis dan menurunkan tingkat efisiensi teknis sebaliknya tanda negatif menunjukkan bahwa semakin tinggi nilai error term akan menurunkan tingkat inefisiensi teknis dan meningkatkan tingkat efisiensi produksi. Berdasarkan hasil analisis menunjukkan bahwa faktor-faktor yang menangkap efek inefisiensi teknis adalah umur peternak, pendidikan dan modal sedangkan pengalaman beternak tidak menangkap efek inefisiensi teknis jika diukur dengan tingkat kepercayaan 95\% ( $\alpha$ 5\%). Pertama, Nilai t-ratio variabel umur bernilai 1,885 dengan nilai $\alpha 5 \%$ tabel 1,665 berarti bahwa semakin tinggi umur maka akan menurunkan inefisiensi teknis dan meningkatkan efisiensi teknis. Hal ini dapat dilihat pada umur, maka rata-rata umur peternak yang $50 \%$ (38 peternak) merupakan peternak dengan 50 tahun ke bawah dan $50 \%$ persen merupakan usia di atas 50 tahun (38 peternak) memberikan pengaruh negatif terhadap penggemukan sapi potong karena tidak terdapat perbedaan dalam mengelola ternak sapi potong karena mereka menggunakan waktu kerja dan metode pengelolaan yang sama meskipun kekuatan fisik dari peternak berbeda-beda dalam mengembangbiakkan sapi potong.

Kedua, nilai t-ratio variabel tingkat pendidikan bernilai 1,87 yang nilainya lebih besar dari t-ratio tabel pada taraf nyata $95 \%$ ( $\alpha 5 \%$ ). Hal ini menunjukkan bahwa semakin tinggi tingkat pendidikan akan meningkatkan tingkat inefisiensi teknis dan menurunkan efisiensi teknis. Kondisi ini menunjukkan bahwa tingkat pendidikan peternak yang baik akan memberikan pengetahuan yang baik terhadap manajemen pengelolaan ternak sapi potong terhadap penggunaan input produksi lebih optimal.. Ketiga, nilai t-ratio dari modal sebesar 2,03 jika dibandingkan dengan $\alpha 5 \%$ dapat menunjukkan bahwa semakin tinggi modal maka akan meningkatkan inefisensi teknis dan menurunkan efisiensi teknis terhadap penggunaan input produksi. Modal merupakan instrumen penting dalam penggemukan sapi dimana alokasi input modal dapat digunakan untuk penggunaan input produksi yang tepat untuk meningkatkan pertambahan bobot sapi potong di Kecamatan Amarasi (Kelurahan Nonbes, Desa Ponain, Desa Kotabes dan Desa Tesbatan). Petani yang memiliki kekuatan modal yang sanga lama membutuhkan modal untuk meningkatkan produksi sapi potong dengan membeli sebagian atau keseluruhan input produksi sapi potong di Kecamatan Amarasi. Menurut Debertin (1986) pemberian input modal dapat menggeser kurva produksi ke atas dengan kata lain modal yang diberikan kepada petani dapat meningkatkan hasil produksi khususnya peningkatan bobot badan sapi.

\section{Simpulan}

Faktor-faktor yang berpengaruh pada penggemukan sapi di Kabupaten Kupang yaitu bobot awal, pakan, vitamin dan aquades sedangkan tenaga kerja dan obat-obatan tidak berpengaruh. Usaha penggemukan sapi di Kabupaten Kupang secara teknis menunjukkan efisien dengan nilai rata-rata efisiensi teknis sebesar 0,982 dan skala usaha menunjukkan skala Decreasing return to scale. Nilai gamma $(\gamma)$ menunjukkan bahwa 44,80 persen error term dari fungs produksi frontier disebabkan oleh faktor internal seperti umur peternak, pengalaman, tingkat pendidikan dan modal sedangkan 55,20 persen disebabkan oleh noise terhadap cuaca dan penyakit. Faktor-faktor yang dapat menangkap efek inefisensi teknis adalah umur peternak, tingkat pendidikan dan modal sedangkan pengalaman beternak tidak menangkap efek inefisiensi teknis.

\section{Pustaka}

[BPS] Badan Pusat Statistik. 2013. Nusa Tenggara Timur dalam Angka. Kupang: Biro Statistik Provinsi Nusa Tenggara Timur. 
Coelli T.J, and D.S.P. Rao, O'Donnell C.J, Battese G.E. 2005. Total Factor Productivity Growth in Agriculture: A Malmquist Index Analysis of 93 Countries. 1980-2000. Agricultural Economics.(32):115-134.

Debertin D.L. 1986. Agricultural Production Economics second edition. New York: Collier Macmillan Publisher.

Nulik J, Yusuf, Marawali H. 2004. Prospek Pengembangan Usaha Sapi Potong dalam Mendukung Agribisnis yang Berdaya Saing di Nusa Tenggara Timur. Balai Pengkajian Teknologi Pertanian Nusa Tenggara Timur.

Saunders M., Lewis P., Thornhill A. 2009. Research Methods for Business Students. Fifth edition (7): 236-237.

Sarwono B dan Arianto B.H. 2001. Penggemukan Sapi Potong Secara Cepat.

Jakarta: Penebar Swadaya. 